\title{
Ballistic impact performance of laminated composite structures
}

\author{
Erdal Camcı ${ }^{1}$, Fehim Findik ${ }^{2,3}$ \\ ${ }^{1}$ Sakarya Applied Science University, Arifiye Vocational School, Arifiye, Sakarya, Turkey; \\ ${ }^{2}$ Sakarya Applied Science University, Faculty of Technology, Metallurgy and Materials Engineering Dept, Esentepe Campus, 54187 \\ Sakarya, Turkey \\ ${ }^{3}$ Sakarya University, BIMAS-RC Research Center, Esentepe Campus, 54187 Sakarya, Turkey
}

\section{Article Info}

Received, 2019

\section{Keyword: \\ Low velocity impact \\ Laminates \\ Impact behavior \\ Ballistic test \\ Failure analysis}

\begin{abstract}
Recently published research indicates that laminated composites have limited applications in advanced structural systems due to their low impact performance. The aim of this study is to give general information about the most commonly used materials and ballistic test methods to the new researchers who want to work on ballistic related subjects. In addition, to summarize the topics related to simulation methods such as FEM and numerical methods which are used most in ballistics. Finally, it is to enlighten them by giving suggestions to the researchers who will work on ballistics in the future.This review paper is focused on the impact resistance and penetration behavior of composites reinforced with fibers as well as their suitability for modern structural applications. The historical development of composite laminates is first reviewed in detail, and notable researchers and their contributions are then reviewed. Also included are reviews on published experimental, numerical, and analytical work on the low velocity impact of composite laminates. Relevant results will be discussed and the recommendations that need to be resolved in the future will be addressed.
\end{abstract}

\section{Corresponding Author:}

Second Author,

Sakarya Applied Science University,

Faculty of Technology,

Department of Metallurgy and Materials Engineering,

Esentepe Campus, 54187 Sakarya, Turkey

Email: findik@sakarya.edu.tr

Tel: +90-264-2956487

\section{Introduction}

Ballistics has been the smart science of mankind since ancient times. One of the most important subclasses of ballistics science is terminal ballistics, and it deals with all the interactions between the target and the bullet. From the aboriginal armor of lightweight composite shielding, ballistics technology has always been advanced and focused on a similar objective.

Experimental investigations can be separated into three main groups related to the impact velocity of the brick. The first group covers the low velocity effect $(\mathrm{Vi}<50 \mathrm{~m} / \mathrm{s})$ in which target plates are normally hit by heavy bullets using a drop hammer or a pneumatic accelerator. The second group includes bullet subsidy and ordnance speed regime $(50<\mathrm{Vi}<1300 \mathrm{~m} / \mathrm{s})$. Mass and shape are started from compressed gas guns or 
powder guns (Figure 1). The final group covers the other ends with high velocity penetration (Vi>1300 m/s). One discussion is the use of metallic laminates for monolithic metal targets. "Metallic laminates have some potential advantages over monolithic metallic armors", counting the ability to be made as thick as possible with homogeneous plates from the same material for a given strength level [1].
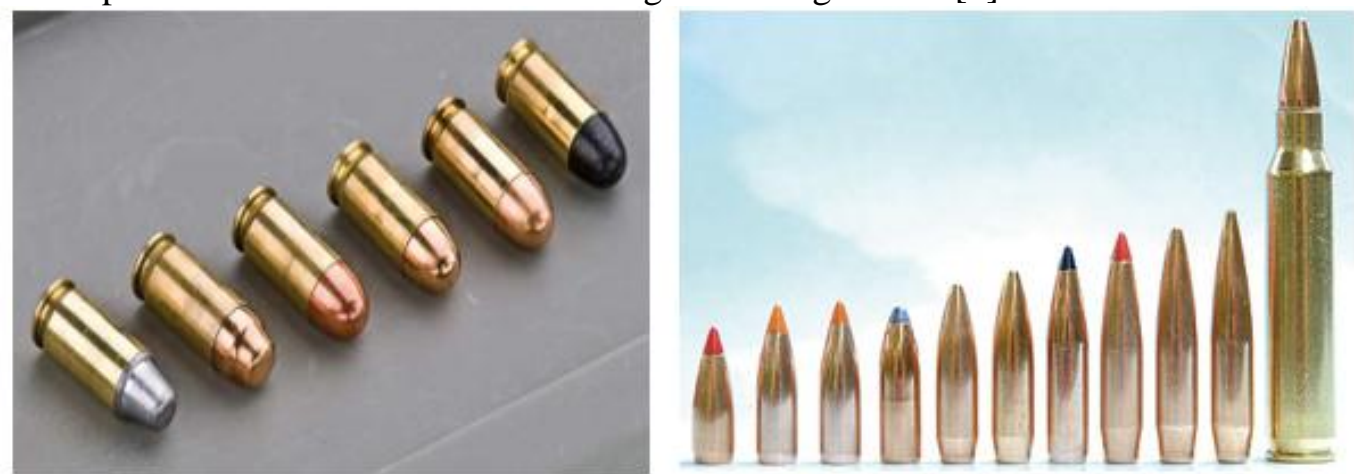

Figure 1. Various bullets in different sizes.

Composite materials have been established for many years as practicable construction materials in almost every sector of the industry. The benefits attained from the combined properties of individual constituent materials make composites an attractive proposition from a number of standpoints, i.e. outstanding strength and stiffness to weight ratio, good corrosion resistance, etc. Simultaneously, they offer a distinctive feature for designing the right material. It deals with the necessities for functionality that are usually free of related compromises with traditional isotropic materials. All users desire good performance and mass production at low cost, but these features are often not available at the same time. This is true in the aerospace industry, especially those components that have a high level of design safety and are cost sensitive. The focus in the automotive industry is quite different from low cost serial production. The excellent corrosion resistance of fiber-reinforced polymer matrix composites makes this particularly attractive to the latest industry [2,3].

Fiber Metal Laminate (FML) is a family of hybrid composites that consists of joining metal plates to a fiberreinforced plastic substrate. The currently used metal can be aluminum, "magnesium, or titanium, and the fiber-reinforced layer is either glass-reinforced, carbon-reinforced or Kevlar-reinforced composite". "By combining isotropic, plastic behavior, durability characteristics, impact resistance, easy repair of metals and high strength, hardness, excellent fatigue, fracture properties of composite materials"; FML has been established as a material with excellent impact properties, excellent fatigue resistance, low density and sufficient corrosion resistance [4]. "Superior fatigue resistance is because of fiber bridging of fatigue cracks as illustrated in Fig. 2, and having a favorable residual stress system between aluminum alloy layers and composite lamina" [5], and exceptional corrosion resistance is due to action of prepregs as a moisture barrier between aluminum layers and vice versa [6].

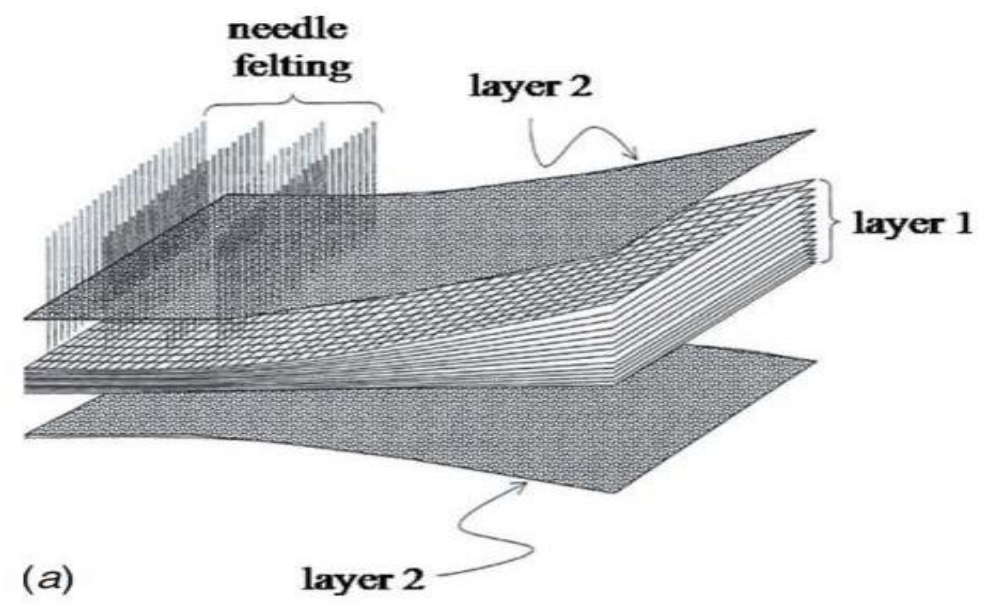

Figure 2. Combination of composite structures: two layers of woven layers and a metal pyramid conical structure between 
FML is the appropriate material that makes use of the advantages of metal when "combined with the composites to increase its impact damage resistance". "Impact involves the effect of the transverse non-linear dynamic load and with the absence of through-thickness reinforcement; transverse impact damage resistance is mostly poor for composites". Because of low strength between the ply, interlaminar stresses (shear and tension) cause delamination complemented with matrix crack and fiber damage.

"It is very important to identify the various failure modes and their propagation towards impact to understand the advantage of including metal with composites in FML. In this paper, low velocity impact response of FML is reviewed with the help of relevant literatures in theoretical, numerical, and analytical studies done by many researchers, and finally the key issues that need to be solved are also addressed".

\section{Experimental studies}

\subsection{Materials}

Several materials are used to monitor the ballistic impact performance of laminated composite structures. These materials can be mentioned as metallic materials (aluminum and steels) and composites.

\section{Aluminum based materials:}

Ubeyli et al [7] published a paper in 2008 about the "investigation on the ballistic behavior of Al2O3/Al2024 laminated composites". In this paper, the effects of mechanical properties of backing material and laminating type, as well as the adhesive type, on the ballistic performance of the composite armor were investigated. The test results showed that utilization of alumina as a front layer and Al2024-T6 as a backing layer in the composites with an alumina/aluminum thickness ratio in the range of 1-3 maintained the highest ballistic performance. Moreover, composites bonded with polyurethane exhibited more resistance to spalling of ceramic tiles than those bonded with epoxy, even though adhesive type had no appreciable effect on the ballistic performance of the composites.

In 2008, Ozsahin [8] investigated on the $\mathrm{PhD}$ thesis of "response of aluminum plates subjected to high velocity impact loads". He analyzed experimentally and numerically of the "influence of projectile velocity, plate thickness and ballistic performance improving techniques e.g. surface coating and adding support on high velocity normal impact resistance of aluminum plates. Four different types of surface coating were applied to plates using plasma spray. Influence of surface coating on ballistic resistance of plates was tested. After the impact, penetration depth, including plate bending on front face and bulging on back face, of the target plate were measured". Development of the ballistic resistance of the plates was perceived in the coated ones. "Both increase in non-perforating projectile velocity and decrease in penetration depth were experienced. Due to the results of the experiments, aluminum 7075 alloys supported with polyethylene, which is the highest resistant, were tested in three different configurations. Bullets were stopped in the configuration sequencing aluminum as a front layer and the polyethylene at the rear side. MSC PATRAN for modeling and MSC DYTRAN for analyzing were used in numerical investigation. Numerical models were conducted on 2024 aluminum alloys of $6.35 \mathrm{~mm}$ thickness and varying bullet velocities". Deformation modes occurring in plate and projectile due to the impact loads are well matched with test results. In numerical investigation, effects of boundary conditions on solution were also analyzed. Results obtained from simulations were compared with those of experiments and a favorable correlation was found between the two.

In 2009, Ozsahin and Tolun [9] reported a study about "influence of layer sequencing on ballistic resistance of polyethylene supported AA 7075 T651 plates". In this study, the effect of layer sequencing was studied experimentally on ballistic resistance of aluminum plates supported by using high molecular weight polyethylene plates. In experiments, 7075 aluminum alloys of T651 heat treatment were used. Three different types of layer sequencing were examined in the study. In experiments, MKEK (Mechanical and Chemical Industry Corporation) made FMJ (Full Metal Jacket) Parabellum bullets of $9 \mathrm{~mm}$ diameter and $19 \mathrm{~mm}$ length were used. The distance between the target plate holder and the shooting system is 5 meters. All shots were normal to target plates. As a result of the experiments, even though three of the layer sequencings had the same thickness, it was clearly observed that the best ballistic performance can be achieved by sequencing the aluminum plate as a front layer and the polyethylene support layer at the rear side. Then, it was clearly 
understood from the test results that plate thicknesses ffect the deformation mechanisms due to high velocity impact.

In 2010, Medvedovski [10-11] reported two papers about "ballistic performance of armor ceramics: Influence of design and structure". He studied the ballistic performance of different armor ceramics, mostly obtained during development, and the designed ceramic-based armor systems. The studied armor ceramics include homogeneous oxide and carbide ceramics and heterogeneous ceramic materials. Composition, structure and main properties of the considered ceramics, which affect ballistic performance, are examined and analyzed.

In 2002, Tarim and co-workers reported two papers [2,3] about "ballistic impact performance of composite structures". In these papers, the ballistic impact performance of several polymer-based composites were experimentally considered. This entailed the manufacture of a number of thermosetting resin composite specimens using the hand lay-up process. Thereafter, ballistic testing was carried out using a variety of commonly obtainable firearms with the resulting properties experimentally obtained using mechanical and ultrasonic methods. They concluded that (a) the thinner composite plates have higher elasticity than the thicker ones in the ballistic testing, (b) the bending and tensile strength are increased with the increments of composite layers, (c) ultrasonic inspection of composite layers after the ballistic testing showed that complete holes occurred in the 18 and 22 layers of composite. However no holes were observed in the 28 and 36 layers of composite, (d) and that the velocity of the bullet is decreased with the increment of layer numbers. In contrast, output is obtained as the opposite behavior of speed, (e) the depth of trace of the bullets is decreased with the increment of layer numbers.

\section{Steels:}

In 2007, Ubeyli et al [12] published a paper "on the comparison of the ballistic performance of steel and laminated composite armors". This study presents the ballistic performance of steel against $7.62 \mathrm{~mm}$ armor piercing projectiles. High strength low alloy steel $(50 \mathrm{CrV} 4)$ was chosen as steel armor for ballistic testing. Three areal density values were kept constant to compare ballistic performance of steel armor specimens with alumina/aluminum laminated composite specimens. In addition, in steel samples, the result of hardness on the ballistic performance was examined. Moreover, failure mechanisms were examined after ballistic testing. According to the experimental results, laminated composites maintained $26 \%$ weight saving compared to steel.

In 2014, Kilic and co-workers [13] studied on the subject of "ballistic behavior of high hardness perforated armor plates against $7.62 \mathrm{~mm}$ armor piercing projectile". "In this paper, some of the important defeating mechanisms of the high hardness perforated plates against $7.62 \times 54$ armor piercing ammunition were investigated. The experimental and numerical results recognized three defeating mechanisms effective on perforated armor plates, which are the asymmetric forces diverges the bullet from its incident trajectory, the bullet core fracture, and the bullet core nose erosion. The initial tests were performed on the monolithic armor plates of 9 and $20 \mathrm{~mm}$ thickness to confirm the devotion of the simulation and material model parameters. The stochastic nature of the ballistic tests on perforated armor plates was analyzed based on the bullet impact zone with respect to holes". Numerous scenarios counting with and without bullet failure models were further investigated to define the mechanisms of the bullet failure. The agreement between numerical and experimental results had considerably increased by comprising the bullet failure criterion and the bullet nose erosion threshold into the simulation.

In 2009, Jena et al [14] researched about the "Ballistic studies on layered structures". This paper presented the ballistic behavior and penetration mechanism of metal-metal and metal-fabric layered structures against 7.62 $\mathrm{mm}$ armor piercing projectiles at a velocity of $840 \pm 15 \mathrm{~m} / \mathrm{s}$ at $30^{\circ}$ angle of impact and compare the ballistic results with that of homogeneous metallic steel armor. This study also define the result of keeping a gap between the target layers. Experimental results presented that among the studied materials, the best ballistic performance was attained with metal-fabric layered structures. The improvements in ballistic performance were analyzed in terms of mode of failure and fracture mechanisms of the samples by using optical and electron microscope, $\mathrm{X}$-ray radiography, and hardness measurement equipment.

In 1999, Borvic and co-workers [15] investigated on the "ballistic penetration of steel plates". This paper presents a study program where the main objective $s$ to investigate the performance of Weldox steel plates impacted by blunt-nosed cylindrical projectiles in the lower ordnance velocity regime. A compressed gas gun was used to do high-precision tests, and a digital camera system was used to photograph the penetration 
process. A joined constitutive model of viscoplasticity and ductile damage was expressed and applied into the non-linear finite element code LS-DYNA, and the material constants for the target plate were determined. The suggested model was applied in simulations of the plate penetration problem and the results compared with test data. Decent agreement between the numerical simulations and the experimental results was found for velocities above the ballistic limit, though the ballistic limit is overvalued by $10 \%$ in the numerical simulations.

In 2014, Yunfei et al [16] published a paper on "experimental investigation on the ballistic performance of double-layered plates subjected to impact by projectile of high strength". In this paper, the ballistic performance of double-layered steel plates of dissimilar materials impacted by blunt- and ogival-nosed projectiles was experimentally studied using a gas gun. The ballistic limit velocity for each configuration was obtained and compared to the study of the effect of layers and the nose shape of projectiles on the ballistic resistance of targets. The experimental results revealed that the ballistic limit velocities are greater for the double-layered plates of the upper layer of high strength and low ductility material. Besides, the ballistic limit velocities of ogival-nosed projectiles are considerably lesser than those of blunt-nosed projectiles.

\section{Composites:}

In 2009, David and his colleagues [17] published a paper about "ballistic resistant body armor: contemporary and prospective materials and related protection mechanisms". In this paper, properties and ballistic resistance mechanisms of such materials have been widely studied. Based on a complete review of the progresses and findings resulting from these studies, protection mechanisms, and performance assessment of several types of anti-ballistic body armor is offered in this investigation. Body armor systems made from dissimilar materials, and displaying distinct ballistic energy absorption mechanisms are argued, and main elements that ffect the ballistic performance and energy absorbing mechanisms of the body armor systems are recognized.

In 2014, Chai and Manikandan [18] reported a review about "low velocity impact response of fiber-metal laminates". The past progress of fiber-metal laminates were reviewed in detail, and prominent scholars and their influences are chronologically tabulated. Included are also reviews on printed experimental and analytical work on the low velocity impact of fiber-metal laminates. Thorough debates were held on the two chief sets of factors, explicitly geometry and material based parameters that inclined the structural response of fiber metal laminates to low-velocity impact. The review completes with full discussions on the future works required for fiber-metal laminates exposed to low velocity impact loads.

In 2016, Bandaru et al [19] reported a paper about "ballistic impact response of Kevlar® reinforced thermoplastic composite armors". The ballistic impact retort of thermoplastic-based composite armors made from Kevlarß fabric and polypropylene (PP) matrix was investigated against ballistic test standard. Interfacial property between PP and Kevlar® was enhanced by adding a coupling agent named as maleic anhydride grafted PP. Abridged density was perceived in Kevlar® thermoplastic-based composites as related to that of the thermoset-based laminates. Ballistic test results exposed that $2 \mathrm{D}$ armor was $2.4-7 \%$ more vulnerable to damage than 3D armors. Hydrocode simulations were performed using ANSYS AUTODYN to achieve an approximation for the ballistic limit velocity and to simulate failure modes. Post-impact damage patterns attained from the simulations were associated with the experimental results to evaluate the performance of the simulations. Decent association between the hydrocode simulations and experiments was obtained, both in terms of failure modes and damage patterns.

In 2002, Ozgultekin [20] researched about "investigation of the composite material combinations for the ballistic armors" in his MSc thesis. In this study, ballistic behaviors of the composite materials used for human body armors were investigated experimentally and numerically. For the initial period of the experimental studies, researchers aimed to acquire the alterations for sequencing the armor layers. By the next period of the experiments, effects and importance of the Aramid fabric positions in the composite combinations were studied. Samples set by dissimilar combination of dissimilar layers that are Kevlar, carbon fiber, resin reinforced polypropylene honeycomb, and steel wire that formed in resin. Safir T14 long-barreled rifle and Yavascalar 36 caliber one-cored projectiles were used to describe ballistic behaviors of the samples. Consequently, it was attained from those dissimilar combinations of the similar materials display dissimilar ballistic behaviors. For the first combinations, fourth and sixth armor samples, and for the second 
combinations, eighth armor specimen protected the human body against the speed of $700 \mathrm{~m} / \mathrm{s}$ projectile from $10 \mathrm{~m}$ distance.

In 2017, Santiago et al [21] published a paper about "impact on thermoplastic fiber-metal laminates: experimental observations". This work examines a new group of fiber metal laminates, termed TFMLs, based on an aluminum alloy and a self-reinforced polypropylene (SRPP). Circular plates were investigated experimentally under situations of localized impact loading. It was detected that the TFML plates outperform glass fiber/epoxy based FMLs under impact circumstances. Limitations, related with the metal/polymer interface and the interlayer toughness, are discussed. The response of this material was characterized over a wide range of strain-rates through the usage of new equipment and techniques. This is of specific significance, given that the mechanical properties of SRPP are documented as being strain-rate dependent. This paper displays extensive experimental data that can be utilized for modeling the response of TFMLs under impact situations.

In 2018, Safri et al [22] investigated on "impact behavior of hybrid composites for structural applications. This paper inspects the impact properties of hybrid composites fabricated with the aim of improving their structural characteristics, and is focused on the impact resistance and penetration behavior of hybrid composites reinforced with natural and synthetic fibers, in addition to their fitness for modern structural applications.

In 2012, Sadighi and co-workers [23] reported a paper on the "impact resistance of fiber-metal laminates". This paper reviews pertinent literature that deals with experimental indication of "material related" and "event related" impact resistance parameters besides the articles related to theoretical and numerical simulation of impact loading of FMLs.

In 2015, Pandya and Naik [24] investigated the "analytical and experimental studies on ballistic impact behavior of carbon nanotube dispersed resin". An analytical formulation is offered for the estimate of ballistic impact performance of multi-walled carbon nanotube (MWCNT) dispersed epoxy resin. The design was based on stress wave propagation and energy balance between the projectile and the target. During the ballistic impact occasion, the energy lost by the projectile is absorbed by the target through numerous damage and energy absorbing mechanisms. Broad failure of the target was owing to catastrophic brittle fracture and shattering. Experimental works were performed on ballistic impact behavior of neat epoxy and MWCNT dispersed epoxy. Characteristic outcomes on ballistic limit velocity and energy absorbed by numerous mechanisms are offered. A decent match is perceived between the analytical and experimental results.

\subsection{Methods}

\section{-Impact Tests}

When the difficulty of penetration courses is taken into consideration, it is not surprising that most of the work in this area is experimental (Figure 3). Velocity impact test methods often differ depending on the number of instrumentation methods provided and the amount of data recorded later. The most common types of tests are the purpose of their purpose [25]:

1. "The velocity and orbit of the projectile before impact.

2. Changes in configuration of projectile and target due to impact.

3. Masses, velocities, and orbits of fragments produced by the impact process.

4. The ballistic limit".

Velocity impact is an energetic process. Some of the incident energy is transformed into light, which confuses the impact incident. Additional difficulties are produced by the debris being discharged at the impact surface and behind the target after the projectile is damaged. "Conventional optical techniques, such as speed cameras, are consequently very restricted for such applications. To overcome these problems, most experimental facilities rely on x-ray illumination of energetic interaction trials". Normally, both x-ray and optical methods are utilized to record impact phenomena. 


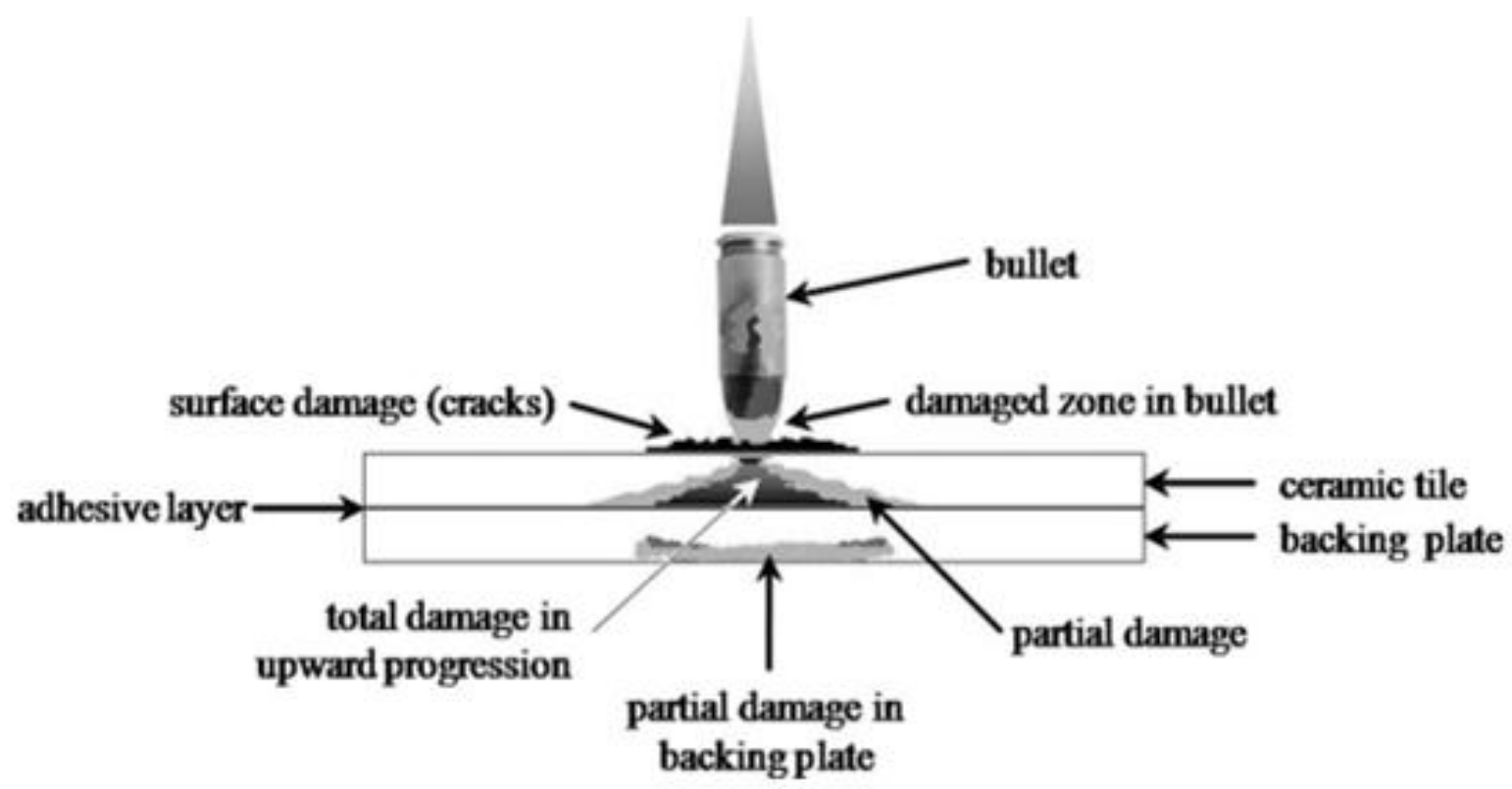

Figure 3. Damage zones in the ceramic tile, backing plate and a projectile (bullet)

Projectile orbits may be decided in a number of methods: speed photography, orthogonal-flash radiography, or yaw-card measurements. Yaw cards are sheets of thin paper or plastic with the expected orbit. The striking velocity is decided on the transition measurement according to the stabilized areas. The period of arrival at prearranged places is recognized by the closing/opening of electrical circuits, disruption of light beams, or flash radiography of the projectile [25].

Muzzle and target mortem measurements include resolving the main dimensions of the target crater in addition to the final length, diameter, and mass of bullets and other massive parts such as depth, diameter, and crater volume [26].

"In summary, the data extracted from conventional velocity impact tests consists of the following:

1. Speed and alignment of the projectile before impact.

2. Speed and alignment of major projectile pieces after perforation.

3. Speed, mass, and spatial deliveries of fragments behind the target.

4. Hole size and mass loss in the target".

Schematic representations of velocity impact data concern relationships among such variables as velocity, target thickness, impact-kinetic energy, and bending (Figure 4). For such plots, physical and geometric characteristics of projectile and target are held constant.

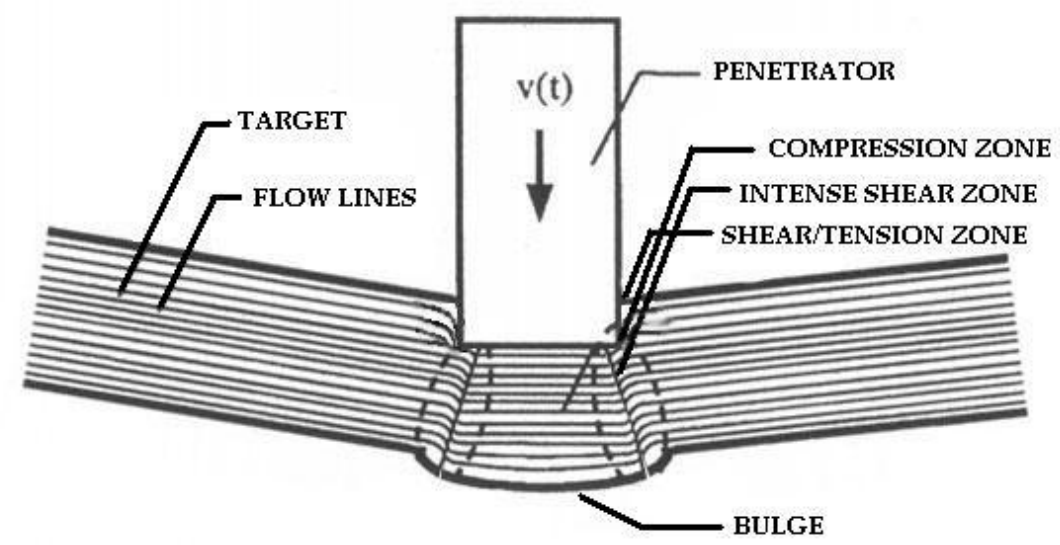

Figure 4. Schematic view of failure mechanisms by bending and plugging [1] 
Perhaps the main shortage of the Charpy impact test is that the small sample is not always an accurate model of the actual condition. Not only does the small sample cause substantial scatter, "but a sample with a thickness of $10 \mathrm{~mm}$ cannot deliver the similar constraint as would be found in a structure with a much greater thickness". At a particular service temperature the standard Charpy sample displays a high shelf-energy, although the similar material in a thick-section structure has low toughness at the similar temperature.

The most rational solution to this problem is the growth of tests that are skillful in handling samples at a minimum thickness of $25 \mathrm{~mm}$. The basic requirement for large samples resulted from the incapability to yield fracture in small laboratory samples at stresses below the gross yield stress, however brittle fractures in ship structures happen at service temperatures at elastic stress levels.

"The first development was an explosion-crack-starter test with a short, brittle weld bead that accumulated on the surface of a steel plate of $350 \times 350 \times 25 \mathrm{~mm}$. The plate was located over a circular die and dynamically loaded with an explosive charge. The brittle weld bead presents a slight natural crack in the test plate similar to a weld-defect crack. The tests are completed over a range of temperature and the appearance of the fracture determines the numerous transition temperatures. Under the nil ductility temperature (NDT) the fracture is a smooth (elastic) fracture running totally to the edges of the test plate. Beyond the NDT a plastic bulge forms in the center of the plate, nevertheless the fracture is still a smooth elastic fracture out to the plate edge. At still higher temperature the fracture does not spread outside of the bulged region. The temperature at which elastic fracture no longer spreads to the edge of the plate is named as the fracture transition elastic (FTE). The FTE results the highest temperature of fracture spread by only elastic stresses. At higher temperatures, the wide plasticity results in a helmet-type bulge. The temperature beyond which this completely ductile tearing happens is the fracture transition plastic" (FTP) (Figure 5).

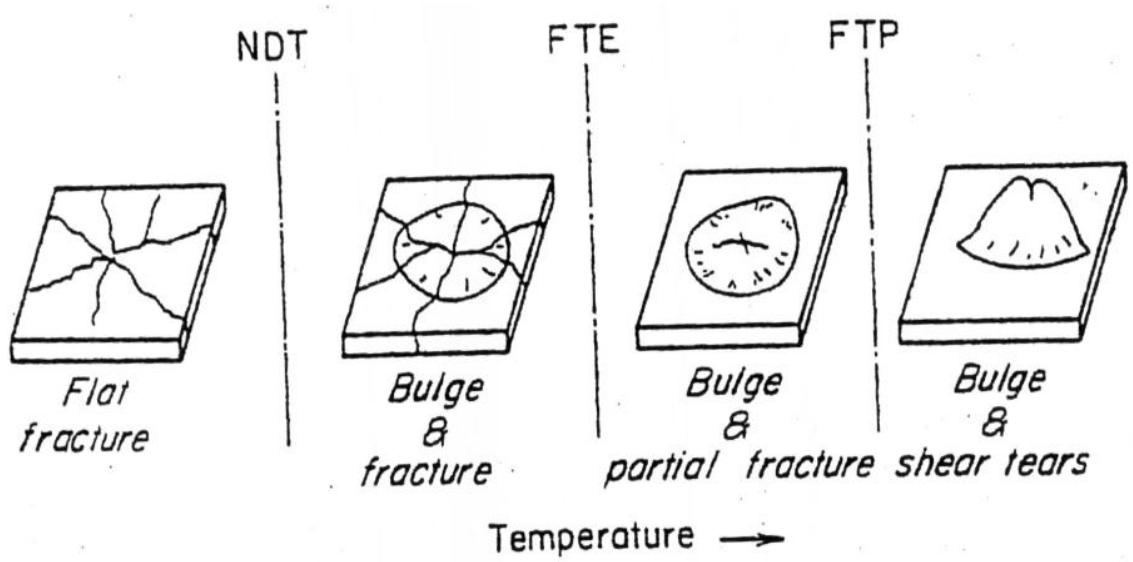

Figure 5 Fracture appearances vs. temperature for explosion-crack-starter test [27]

\section{-Drop Weight Tests}

The drop weight test was settled for the decided NDT (nil ductility temperature) on full thickness plates [28]. Drop-weight can also be utilized in metal forming operations because it is simple and economical in design. Lately, it is also underway to be utilized as a ballistic test technique.

"The drop-weight test (DWT) was established for the determination of the NDT on full thickness plates. A small bead of brittle weld metal is dropped on the surface of a plate, usually $90 \times 350 \times 15$ to $25 \mathrm{~mm}$ in thickness. A slight notch is presented in the weld bead and the sample reinforced as a simple beam in a persistent temperature bath. The brittle weld bead is cracked at near yield-stress levels because of dynamic loading from a falling weight. The anvil stop confines the bending of the sample. Subsequently the sample is a wide beam loaded in three-point bending, this constraint limits the stress on the tension face of the plate to a value that does not surpass the yield stress. If the starter-crack propagates across the width of the plate on the tension surface to the edges, the test temperature is under the NDT. Whole separation on the compression side 
of the sample is not essential. The NDT is the maximum temperature at which a nil ductility break is formed. The test is fairly reproducible and the NDT can be dogged to the adjacent $5^{\circ} \mathrm{C}$ " [27].

A drop-weight contains an anvil carrying lower die and upper support, which guides a dropping weight and a device to increase the falling weight to the preferred height. The falling weight produces necessary energy by falling from the elevated height. A modest drop weight machine can be shown in Figure 6.

Some of the energy is lost in the guides because of opposite frictional forces. The machine frame engrosses definite quantity of the energy because of vibration of dissimilar parts. This is owing to the allocation of the momentum from the ram.

The sample will similarly engross definite quantity of the energy in the form of plastic deformation.
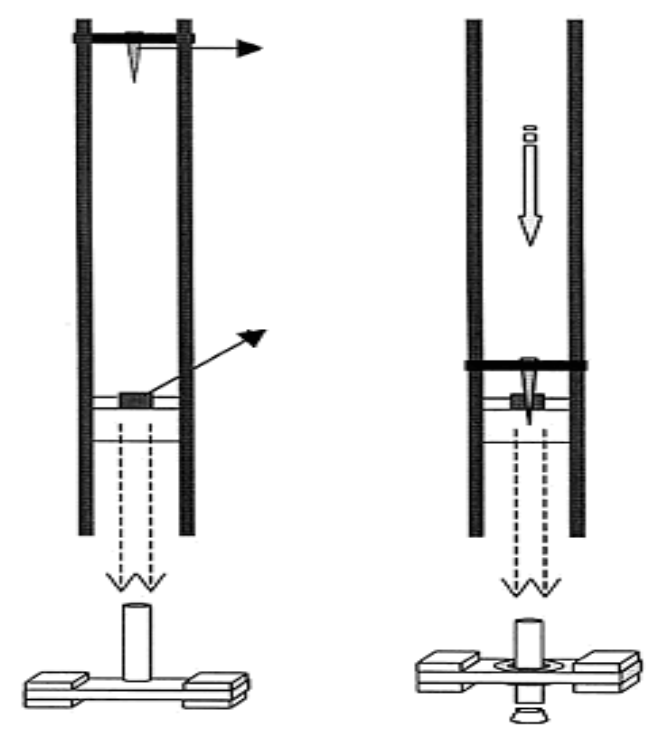

Figure 6 Schematic view of a drop-weight machine [27]

It is obvious that, in gravity drop hammer, the acceleration of the ram is somewhat below the gravitational acceleration $(\mathrm{a}<\mathrm{g})$, because of frictional losses. Then the acceleration of the ram is directly proportional to the weight of the ram [29].

\section{-Ballistic Tests}

The ballistic tests were used by previous researchers $[1,2,3,30]$ on the steels as well as the composites. The objective of the test is to supplement current ballistic testing events and to begin a steady and dependable means of assessing the resistance to sharp instrument penetration of body armor. This test is proposed to reflect the effect of hand delivered impact of sharp, pointed instruments whose point or tip is not offset more than $19.05 \mathrm{~mm}$ from the center-line of the fist(s) delivering the impact [31].

The origin of these events is the formation of a steady and repeatable sharp instrument impact, which is characteristic of:

- "a characteristic sharp apparatus which may be utilized to overthrow the protection of ballistic body armor; - the maximum energy with which such an apparatus could be hand provided by a healthy, athletic male with no physical illnesses. 
As a result, $18 \mathrm{~kg}$ weight falling from a static position located $121 \mathrm{~cm}$ beyond the test impact surface is appropriate for the test. Such that the subsequent theoretical kinetic energy is 13 joule, the subsequent theoretical translational momentum is $9 \mathrm{~kg}$-seconds, and the subsequent theoretical striking velocity is $484 \mathrm{~cm}$ per second. These values are theoretical, in as much as the calculations assume the potential energy to be wholly transformed into kinetic energy, ignoring that portion of the potential energy really transformed into friction, heat, sound, etc." [31].
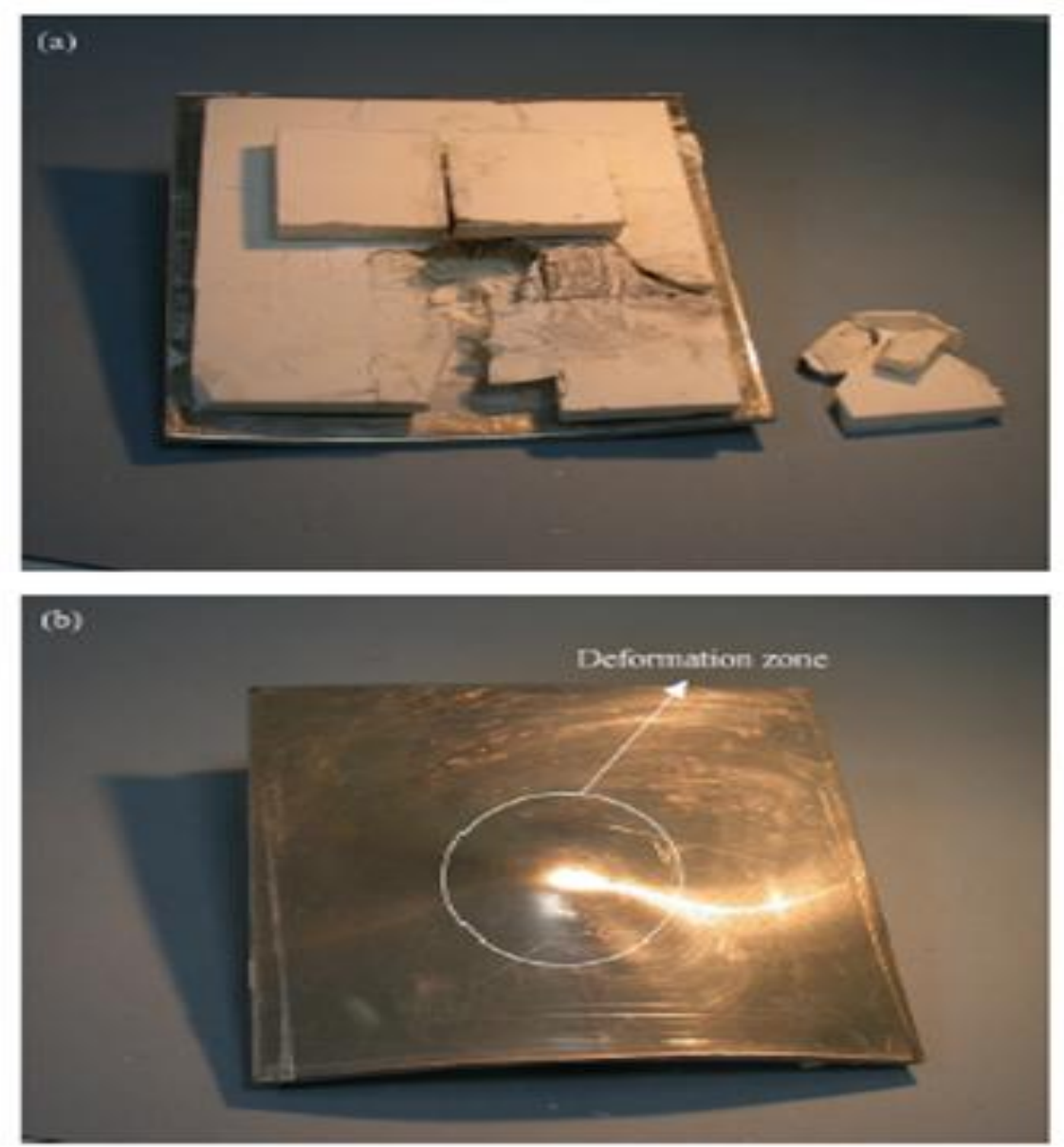

Figure 7. Front (a) and rear (b) views of the sample R6 using A12024-O and polyurethane bonding after impact of $7.62 \mathrm{~mm}$ projectile [31]

\section{Modeling (simulation)}

\section{-FEM}

Despite reporting many investigations into the modeling of composite structures using FEM, only selected studies will be reviewed here.

In a previous study [32], the authors investigated "ballistic impact response of Kevlar reinforced thermoplastic composite armors" experimentally as well as simulation using FEM method. Researchers concluded that the employed simulations were in good correlation with the test results, which shows the capability of the simulations. 
The related study [32] highlighted the use of thermoplastic-based composite laminates with dissimilar fabric architectures and design forecasts that could be used to plan a lightweight body armor that meets the supplies set in test standards from government agencies.

In the other study [20], the investigator reported a thesis about "composite material combinations for the ballistic armors" using impact tests as well as FEM method using ANSYS/LSDYNA software. In this study, samples set by different combination of dissimilar layers that are Kevlar, carbon fiber, resin reinforced polypropylene honeycomb, and steel sifter wire that formed in resin. Safir T14 long-barreled rifle and Yavascalar 36 caliber one-cored projectiles were used to describe ballistic actions of the samples. This study illustrated that those dissimilar combinations of the same materials show diverse ballistic behaviors. For the first combinations of the same materials show diverse ballistic behaviors. For the first combinations, fourth and sixth armor specimens, and for the second combinations, eighth armor specimen was protected the human body against the speed of $700 \mathrm{~m} / \mathrm{s}$ projectile from $10 \mathrm{~m}$ distance.

In ref 15, the researchers published a paper about "ballistic penetration of steel plates" using ballistic tests, as well as non-linear finite element code LS-DYNA. In this study, the proposed model is applied in simulations of the plate penetration problem and the results are compared with test data. Good agreement between the numerical simulations and the experimental results is found for velocities well with the ballistic limit, while the ballistic limit itself is overestimated by approximately $10 \%$ in the numerical simulations.

In ref 20, the authors have published a review paper about the "impact resistance of fiber-metal laminates" using experiments and simulation work using finite element method and they have seen a good match between the experimental results with the modeling work.

In a recent $\mathrm{PhD}$ study [30], Iyibilgin investigated the "impact and penetration analysis using of CAD/CAE systems" in his PhD thesis. In this study LS-DYNA FE Code was employed to study the penetration of impactor through steel armor. The work was carried out through two routes, experimental and analytical. Experimental work was done for 10,15, $20 \mathrm{~mm}$ thickness targets with impactor striking velocities of 800, $1000,1500 \mathrm{~m} / \mathrm{sec}$ and with conic, cylindrical and square impactor ends. Through the analytical route the system was modeled and analyzed. Besides, laminate target systems were also modeled and analyzed. Laminate combinations were steel-steel-steel, steel-titanium-steel, steel-rubber-steel and steel-air gap-steel. The analytical outcomes were attained and matched with the experimental result. The outcome indicated good correlation between experimental and FE results. It was concluded that the optimum results were obtained in using steel-air gap-steel laminate target. Lastly it is also concluded the benefit of CAD/CAE systems to attain optimum solutions with minimum costs.

Davies [33] established a FEM code to study the hardly visible damage of impacted composites. He succeeded to predict the dynamic responses like force, deflection, and strain histories through his code. In his modeling transverse shear deformation effect was combined for the target plate. Later, many papers related to the numerical modeling of impact damage of composite laminates (Figure 8) are found [33-34]. Most of the academics use the commercial software such as ABAQUS, LS-DYNA etc.
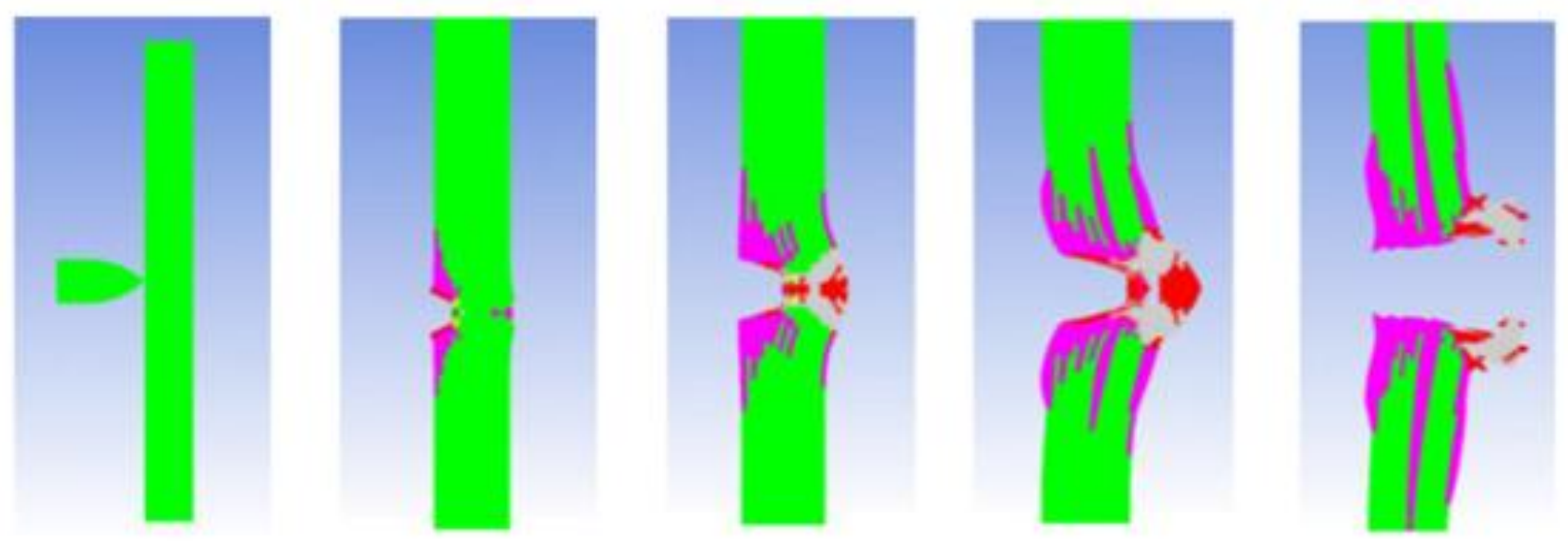

Figure 8. Damage propagation through simulations $(400 \mathrm{~m} / \mathrm{s})[34]$ 
Concerning sandwich structures, many investigators have attempted to model the low-velocity impact response and capture the various failure modes [18,23]. The general advances and outcomes in this situation was reviewed and stated in [23]. Comparable to material model for composites, implementing a 3-D stressbased damage model for composite sandwich structures displays good correlation with the experiments [30].

\section{-Numerical methods}

In 2011, Flores-Johnson et al [35] reported a paper about "ballistic performance of multi-layered metallic plates impacted by a 7.62-mm APM2 projectile" via numerical simulation using the LS-DYNA finite element code. It was found that monolithic plates have a better ballistic performance than that of multi-layered plates made of the same material. This influence weakens with impact velocity. It was also observed that doublelayered plates with a thin front plate of aluminum and thick back steel plate display greater resistance than multi-layered steel plates with comparable areal density.

In 2014, Kilic et al [13] published a paper about "ballistic behavior of high hardness perforated armor plates against $7.62 \mathrm{~mm}$ armor piercing projectile" experimentally and numerically. In this study, the numerical models were established using Lagrange discretization in LS-DYNA with several cases counting with and without bullet failure model. Consequently, good relationships were shown between the simulation and experimental penetration depths of the base armor and the deformation patterns of the perforated plate after the ballistic tests. The outcomes also inferred that high hardness multilayer perforated plates could be used successfully in ballistic protection and had a potential of lessening areal mass efficiency meaningfully.

In 2015, Pandya and Naik [36] investigated"analytical and experimental studies on ballistic impact behavior of carbon nanotube dispersed resin". In this paper, experimental studies are carried out on ballistic impact behavior of neat epoxy and MWCNT dispersed epoxy. Typical results on ballistic limit velocity and energy absorbed by numerous mechanisms are offered. Ballistic impact behavior of neat epoxy resin and MWCNT dispersed epoxy resin are matched. A decent match is perceived between the analytical and experimental results.

\section{Future perspective}

Substantial efforts to clarify impact properties of FMLs have responded with various pertinent enquiries. However, to attain a complete recognizing of the issue, there is a long way; several steps of which are itemized underneath:

i. "There are a limited number of articles concerning theoretical modeling of impact response of FMLs. Numerous potentials to change parameters related to the material and configuration of FMLs, make the experimental investigations so difficult and costly, such a modeling would be more valuable and highly cost effective in design and analysis of FMLs components and structures [23].

ii. Some parameters, such as number of layers and different layup and configurations, need more attention to investigate their effects on the impact response and damage initiation and propagation. A full and step-by-step comparative study is recommended to clarify all aspects of impact behavior of FMLs based on thermoset and thermoplastic matrices [23].

iii. It seems the future application of FMLs mainly depends on the development of new metal alloys, fibers and their combinations within laminates [37]. Different geometries of the specimen, boundary conditions, and various positions of impact point as well as effect of multiple impacts are recommended to be considered in the future research in this field".

iv. The interlaminar shear strength and transverse flexural strength of unidirectional fiber composites is roughly inversely proportional to the square of void content in the composites, which highlights the importance of fabrication of high quality composites [38]. A high fiber volume fraction (>60 vol\%) is essential for fiber-reinforced composites to maintain their superior performance with specified stiffness and strength in comparison with high-performance light metallic alloys [39]. 
v. Significantly less research has been performed in ballistic impact performance using natural fibers including Kevlar. Keeping the advantages of natural fibers, such as cheapness and high strength, more research is needed for suitable design as well as the similar mechanical properties.

vi. For the application of high temperature environment, the thermal stability of laminated composites needs to be improved. This can be achieved in composites by means of more thermally stable fibers like zirconia, graphite, silicon carbide as well as $\mathrm{Be}-\mathrm{Al}, \mathrm{Cu}-\mathrm{Ni}$ and $\mathrm{Ni}-\mathrm{Ti}$ alloys, carbon and alloy steels.

vii. To improve the ballistic impact performance, further studies need to be done about the following different materials and design groups:

- Epoxy/aramid fiber, Quasi-Isotropic Laminate (Q1) $\left[0 /+45 /-45 / 90^{\circ}\right]$ and Unidirectional lamina (UD),

- Tungsten carbide-cobalt,

- Polyurethane foam (flexible closed cell),

- High strength low alloy,

- TPA/PEBA (Thermoplastic polyamide elastomer/Polyether block amide,

- $\quad 2014, \mathrm{~T} 3 \mathrm{Al} /$ aramide fiber, UD composite ( $0^{\circ}$ ve $90^{\circ}$ lamina $)$,

- $\quad 7075, \mathrm{~T} 761 \mathrm{Al} /$ aramide fiber, UD composite $\left(0^{\circ}\right.$ ve $90^{\circ}$ lamina $)$,

- Epoxy/high strength (HS) carbon fiber (fabric), UD laminate $90^{\circ}$,

- Epoxy/S-glass fiber, UD laminate $90^{\circ}$,

- Bismaleimide (BMI)/HS carbon fiber, UD laminate, $90^{\circ}$,

- PEEK /IM (intermediate modulus) carbon fiber, UD laminate, $90^{\circ}$,

- Polyimide/HS carbon fiber (fabric), biaxial laminate,

- BMI/HS carbon fiber, UD laminate, $0^{\circ}$ and biaxial laminate,

- PEEK/IM carbon fiber, UD laminate, $0^{\circ}$ laminate.

viii. Further work is needed on laminated composite structures to achieve lightness, cheapness, ergonomic, mobility, and ease of production.

ix. In case of using $\mathrm{Al}$ as a part of the laminated composite structures, coating ( $\mathrm{Cr}$ or $\mathrm{Zr}$ based plasma vapor deposition) could be useful to increase the hardness and ballistic performance.

x. Despite using macro- and micro-structures in the laminated composites, nanostructures could also be beneficial to increase the ballistic performance.

xi. Different support layers (hard metals and ceramics) could be used in various designs of the laminated structures to decrease the ballistic impact of the bullets via diverting the nose of the bullet (Figure 9).

xii. In various armor systems, different fabrics (such as Kevlar, Twaran, Flax, Hemp etc) could be used together with the silica, rubber, PP and other materials for better ballistic performance.

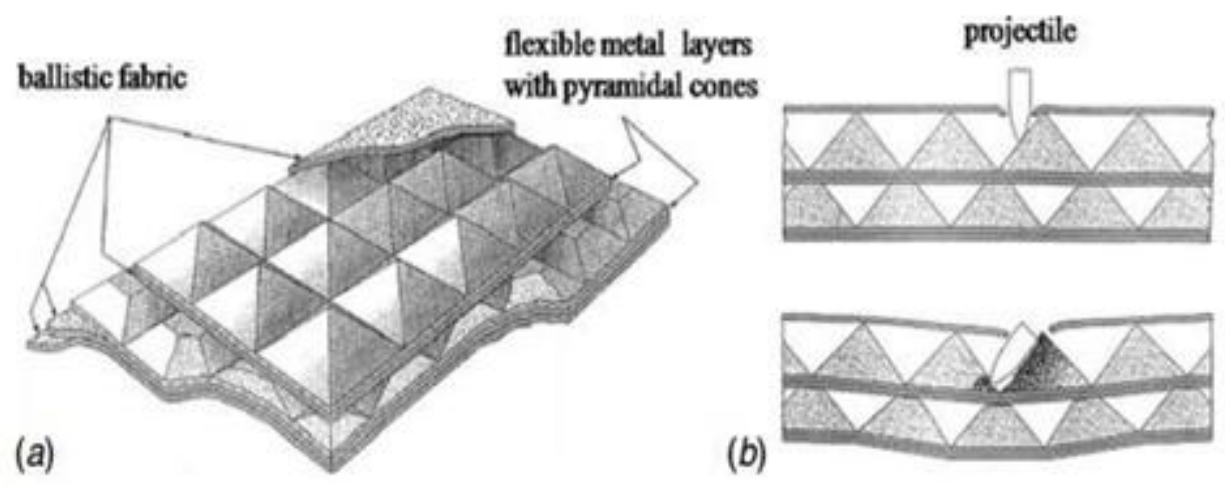

Figure 9. (a) Compound body armor design and (b) penetration of a projectile followed by the deflection of its trajectory [40] 


\section{Conclusion}

In the past 20 years, numerous experiments have demonstrated that FMLs show superior impact properties relative to bare aluminum sheets of the same areal densities. "In this paper, the low-velocity impact characteristics of FML were discussed based on the previous research articles contributing to experimental, numerical and analytical solution methods. Some of the important conclusions and future research work possibilities are summarized below":

- Generally aluminum, steels, and composites can be used in the ballistic impact issues of laminated composite structures. Utilization of alumina as a front layer and Al2024-T6 as a backing layer in the composites bonded with polyurethane exhibited more resistance to spalling of ceramic tiles than those bonded with epoxy, even though adhesive type had no appreciable effect on the ballistic performance of the composites.

- "Aluminum 7075 alloys supported with polyethylene, which is the highest resistant, were tested in three different configurations. Bullets were stopped in the configuration sequencing aluminum as a front layer and the polyethylene at the rear side".

- The best ballistic performance can be achieved by sequencing the aluminum plate as a front layer and the polyethylene support layer at the rear side.

- In some polymer-based composites, (a) the thinner composite plates have higher elasticity than the thicker ones in the ballistic testing, (b) the bending and tensile strength are increased with the increments of composite layers, and (d) the velocity of the bullet is decreased with the increment of layer numbers. In contrast, output is obtained as the opposite behavior of speed, (e) the depth of trace of the bullets are decreased with the increment of layer numbers.

- Impact test, drop weight test, and ballistic tests are used for the impact performance of laminated composites.

- To save the time and money, modeling and numerical methods can be used to monitor the ballistic impact performance of laminated composite structures. Different software (ANSYS, ABACUS, NASTRAN etc) can be used in non-linear finite element method code LS-DYNA.

- Further work is needed on laminated composite structures to achieve lightness, cheapness, ergonomic, mobility, and ease of production. In case of using $\mathrm{Al}$ as a part of the laminated composite structures, coating could be useful to increase the hardness and ballistic performance. In various armor systems, different fabrics could be used together with the silica, rubber, PP and other materials for better ballistic performance.

\section{References}

[1] Y. E. Kalay, "Low velocity impact characterization of monolithic and laminated a 2024 plates by drop weight test", MSc thesis, METU, 2003.

[2] N. Tarim, F. Findik, H. Uzun, "Ballistic Impact Performance of Composite Structures", Composite Structures, vol. 56(1), pp. 13-20, 2002.

[3] F. Findik and N. Tarim, "Ballistic impact efficiency of polymer composites", Composite Structures, vol. 61(3), pp. 187-192, 2003.

[4] W. Guocai, "The mechanical behavior of GLARE laminates for aircraft structures", JOM, pp. 72-79, 2005.

[5] A. Vlot, "Impact properties of fiber metal laminates", Compos Eng, vol, 3, pp. 911-27, 1993.

[6] A. Vlot, "Impact loading on fiber metal laminates", Int J Impact Eng, vol. 18, pp. 291-307, 1996.

[7] M. Ubeyli, R. O. Y1ldırım, B. Ogel, "Investigation on the ballistic behavior of $\mathrm{Al}_{2} \mathrm{O}_{3} / \mathrm{Al} 2024$ laminated composites", J of Materials Processing Technology, vol. 196, pp. 356-364, 2008

[8] B. Özşahin, "Behavior of Al sheets under high impacted loads", PhD thesis, ITU, 2008. 
[9] E. Özşahin and S. Tolun, "Effect of layer arrangement on ballistic strength in polyethylene reinforced AA 7075 T651 plates", ITU Magazine, vol. 8(2), pp. 72-80, 2009.

[10] E. Medvedovski, "Ballistic performance of armor ceramics: Influence of design and structure Part 1", Ceramics International, vol. 36, pp. 2103-2115, 2010.

[11] E. Medvedovski, "Ballistic performance of armor ceramics: Influence of design and structure Part 2", Ceramics International, vol. 36, pp. 2117-2127, 2010.

[12] M. Ubeyli, R. O. Yıldırım, B. Ogel, "On the comparison of the ballistic performance of steel and laminated composite armors", Materials and Design, vol. 28, pp. 1257-1262, 2007.

[13] N. Kılıc, S. Bedir, A. Erdik, B. Ekici, A. Tasdemirci, M. Guden, "Ballistic behavior of high hardness perforated armor plates against $7.62 \mathrm{~mm}$ armor piercing projectile", Materials and Design, vol. 63, pp. 427-438, 2014.

[14] P. K. Jena, K. Ramanjeneyulu, K. S. Kumar, T. B. Bhat, „Ballistic studies on layered structures”, . Materials and Design, vol. 30, pp. 1922-1929, 2009.

[15] T. Borvik, M. Langseth, O. S. Hopperstad, K. A. Malo, "Ballistic penetration of steel plates", Int. Journal of Impact Engineering, vol. 22, pp. 855-886, 1999.

[16] D. Yunfei, Z. Wei, Y. Yonggang, S. Lizhong, W. Gang, "Experimental investigation on the ballistic performance of double layered plates subjected to impact by projectile of high strength", Int. Journal of Impact Engineering, vol. 70, pp. 38-49, 2014.

[17] N. V. Davis, X. L. Gao, J. Q. Zheng, "Ballistic Resistant Body Armor: Contemporary and Prospective Materials and Related Protection Mechanisms", Applied Mechanics Reviews, vol. 61, pp. 1-19, 2009.

[18] G. B. Chai and P. Manikandan, "Low velocity impact response of fiber-metal laminates - A review", Composite Structures, vol. 107, pp. 363-381, 2014.

[19] A. K. Bandaru, V. V. Chavan, S. Ahmad, R. Alagirusamy, N. Bhatnagar, "Ballistic impact response of Kevlar® reinforced thermoplastic composite armors”, Int. Journal of Impact Engineering, vol. 89, pp. 113, 2016.

[20] S. E. Ozgultekin, "Investigation of composite material combinations used in ballistic arms", MSc Thesis, SAU, 2012.

[21] R. Santiago, W. Cantwell, M. Alves, "Impact on thermoplastic fibre-metal laminates: Experimental observations", Composite Structures, vol. 159, pp. 800-817, 2017

[22] S. N. A. Safri, M. T. H. Sultan, M. Jawaid, K. Jayakrishna, "Impact behavior of hybrid composites for structural applications", Composites Part B, vol. 133, pp. 112-121, 2018.

[23] M. Sadighi, R. C. Alderliesten, R. Benedictus, "Impact resistance of fiber-metal laminates", Int. Journal of Impact Engineering, vol. 49, pp. 77-90, 2012.

[24] K. S. Pandya, N. K. Naik, "Analytical and experimental studies on ballistic impact behavior of carbon nanotube dispersed resin", Int. Journal of Impact Engineering, vol. 76, pp. 49-59, 2015.

[25] J. A. Zukas, T. Nicholas, H. F. Swift, L. B. Greszczuk, D. Curran, "Impact Dynamics", pp. 155-214, John Wiley \& Sons Inc, 1982.

[26] J. P. Lambert and B. E. Ringers, Ballistic Research Laboratory, ARBRL-TR-02066, 1978.

[27] G. E. Dieter, "Mechanical Metallurgy", McGraw-Hill Inc, 1988.

[28] ASTM Standards, pt. 31, pp. 582-601, Designation E208-69, 1969.

[29] A. Çolakoğlu, "Design and Construction of a Gravity Drop Hammer", MSc Thesis, Mechanical Engineering Department, METU, 2002.

[30] O. Iyibilgin, "Use of CAD/CAE for impact and penetration analysis", $\mathrm{PhD}$ thesis, Sakarya University, 2004.

[31] HP White Laboratory. Sharp Instrument Penetration of Body Armor Inc. Test Procedures. HPW-TP0400.03, 1994. 
[32] A. K. Bandaru, V. V. Chavan, S. Ahmad, R. Alagirusamy, N. Bhatnagar, "Ballistic impact response of Kevlar® reinforced thermoplastic composite armors", Int Journal of Impact Engineering, vol. 89, pp. 113, 2016.

[33] G. A. O. Davies, X. Zhang, G. Zhou, S. Watson, "Numerical modeling of impact damage”, Composites, vol. 25, pp. 342-50, 1990.

[34] X. Zhang, "Impact damage in composite aircraft structures- experimental testing and numerical simulation", ImechE, Part G. J Aerospace Eng, vol. 212, pp. 245-59, 1998.

[35] E. A. Flores-Johnson, M. Saleh, L. Edwards, "Ballistic performance of multi-layered metallic plates impacted by a 7.62-mm APM2 projectile", Int Journal of Impact Engineering, vol. 38, pp. 1022-1032, 2011.

[36] K. S. Pandya, N. K. Naik, "Analytical and experimental studies on ballistic impact behavior of carbon nanotube dispersed resin”, Int Journal of Impact Engineering, vol. 76, pp. 49-59, 2015.

[37] S. E. M. Torshizi, S. Dariushi, M. Sadighi, P. Safarpour, "A study on tensile properties of a novel fiber metal laminates", Mater Sci Eng A, vol. 527, pp. 4920-4925, 2010.

[38] P. Linde, J. Pleitner, H. de Boer, C. Carmone, "Modeling and simulation of fiber metal laminates", In: ABAQUS Users' Conference, Boston, Massachusetts, pp. 421-439, 2014.

[39] R. Alderliesten, “On the development of hybrid material concepts for aircraft structures", Recent Patents on Engineering, vol. 3, pp. 25-38, 2009.

[40] G. R. Villanueva and W. J. Cantwell, "The high velocity impact response of composites and FMLreinforced sandwich structures", Composites Sci Technol, vol. 64, pp. 35-54, 2004. 